\title{
Bilingualism: Consequences for Mind and Brain
}

\section{Citation}

Bialystok, Ellen, Fergus I. M. Craik, and Gigi Luk. 2012. Bilingualism: Consequences for Mind and Brain. Trends in Cognitive Sciences 16, no. 4:240-250.

\section{Published Version}

doi:10.1016/j.tics.2012.03.001

\section{Permanent link}

http://nrs.harvard.edu/urn-3:HUL.InstRepos:10587326

\section{Terms of Use}

This article was downloaded from Harvard University's DASH repository, and is made available under the terms and conditions applicable to Open Access Policy Articles, as set forth at http:// nrs.harvard.edu/urn-3:HUL.InstRepos:dash.current.terms-of-use\#OAP

\section{Share Your Story}

The Harvard community has made this article openly available.

Please share how this access benefits you. Submit a story.

\section{Accessibility}




\title{
Bilingualism: Consequences for Mind and Brain
}

\author{
Ellen Bialystok, \\ York University \\ Fergus I.M. Craik, and \\ Rotman Research Institute of Baycrest \\ Gigi Luk \\ Harvard Graduate School of Education
}

\begin{abstract}
Building on earlier evidence showing a beneficial effect of bilingualism on children's cognitive development, we review recent studies using both behavioral and neuroimaging methods to examine the effects of bilingualism on cognition in adulthood and explore possible mechanisms for these effects. This research shows that bilingualism has a somewhat muted effect in adulthood but a larger role in older age, protecting against cognitive decline, a concept known as "cognitive reserve". We discuss recent evidence that bilingualism is associated with a delay in the onset of symptoms of dementia. Cognitive reserve is a crucial research area in the context of an aging population; the possibility that bilingualism contributes to cognitive reserve is therefore of growing importance as populations become increasingly diverse.
\end{abstract}

\section{Why bilingualism?}

It is generally believed that more than half of the world's population is bilingual [1]. In each of the U.S. [2] and Canada [3], approximately $20 \%$ of the population speaks a language at home other than English. These figures are higher in urban areas, rising to about $60 \%$ in Los Angeles [4] and 50\% in Toronto [3]. In Europe, bilingualism is even more prevalent: In a recent survey, $56 \%$ of the population across all European Union countries reported being functionally bilingual, with some countries recording particularly high rates, such as Luxembourg at 99\% [5]. Bilinguals, therefore, make up a significant portion of the population. Importantly, accumulating research shows that the development, efficiency, and decline of crucial cognitive abilities are different for bilinguals than for monolinguals. What are these cognitive differences and how does bilingualism lead to these changes?

The context for examining how bilingualism affects cognitive ability is functional neuroplasticity, the study of how experience modifies brain structure and brain function. Such modifications have been found following experiences as diverse as juggling [6], videogame playing [7], careers in architecture [8] taxi-driving [9], and musical training [10, 11]. Bilingualism is different from all of these: like juggling and playing video games it is intense, and like architecture and driving taxis in London it is sustained, but unlike these experiences, bilinguals are not typically pre-selected for talent or interest. Although bilinguals undoubtedly differ from monolinguals in certain ways, they generally did not

\footnotetext{
(C) 2012 Elsevier Ltd. All rights reserved.

Publisher's Disclaimer: This is a PDF file of an unedited manuscript that has been accepted for publication. As a service to our customers we are providing this early version of the manuscript. The manuscript will undergo copyediting, typesetting, and review of the resulting proof before it is published in its final citable form. Please note that during the production process errors may be discovered which could affect the content, and all legal disclaimers that apply to the journal pertain.
} 
choose bilingualism. Rather, the circumstances of their family, place of birth, or immigration history simply required that they learn more than one language.

\section{What is different about bilingual minds?}

It has long been assumed that childhood bilingualism affected developing minds but the belief was that the consequences for children were negative: learning two languages would be confusing [12]. A study by Peal and Lambert [13] cast doubt on this belief by reporting that children in Montreal who were either French-speaking monolinguals or English-French bilinguals performed differently on a battery of tests. The authors had expected to find lower scores in the bilingual group on language tasks but equivalent scores in nonverbal spatial tasks, but instead found that the bilingual children were superior on most tests, especially those requiring symbol manipulation and reorganization. This unexpected difference between monolingual and bilingual children was later explored in studies showing a significant advantage for bilingual children in their ability to solve linguistic problems based on understanding such concepts as the difference between form and meaning, that is, metalinguistic awareness [14-20] and nonverbal problems that required participants to ignore misleading information [21,22].

Research with adult bilinguals built on these studies with children and reported two major trends. First, a large body of evidence now demonstrates that the verbal skills of bilinguals in each language are generally weaker than are those for monolingual speakers of each language. Considering simply receptive vocabulary size, bilingual children [23] and adults [24] control a smaller vocabulary in the language of the community than do their monolingual counterparts. On picture-naming tasks, bilingual participants are slower [25$28]$ and less accurate $[29,30]$ than monolinguals. Slower responses for bilinguals are also found for both comprehending [31] and producing words [32], even when bilinguals respond in their first and dominant language. Finally, verbal fluency tasks are a common neuropsychological measure of brain functioning in which participants are asked to generate as many words as they can in 60 seconds that conform to a phonological or semantic cue. Performance on these tasks reveals systematic deficits for bilingual participants, particularly in semantic fluency conditions [33-37], even if responses can be provided in either language [38]. Thus, the simple act of retrieving a common word is more effortful for bilinguals.

In contrast to this pattern, bilinguals at all ages demonstrate better executive control than monolinguals matched in age and other background factors. Executive control is the set of cognitive skills based on limited cognitive resources for such functions as inhibition, switching attention, and working memory [39]. Executive control emerges late in development and declines early in aging, and supports such activities as high level thought, multi-tasking, and sustained attention. The neuronal networks responsible for executive control are centered in the frontal lobes, with connections to other brain regions as necessary for specific tasks. In children, executive control is central to academic achievement [40], and in turn, academic success is a significant predictor of long term health and well being [41]. In a recent meta-analysis, Adesope et al. [42] calculated medium to large effect sizes for the executive control advantages in bilingual children and Hilchey and Klein [43] summarized the bilingual advantage over a large number of studies with adults. This advantage has been shown to extend into older age and protect against cognitive decline [25, 44, 45], a point we return to below.

In this review, we examine the evidence for bilingual advantages in executive control and explore the possible mechanisms and neural correlates that may help to explain them. Our conclusion is that lifelong experience in managing attention to two languages reorganizes 
specific brain networks, creating a more effective basis for executive control and sustaining better cognitive performance throughout the lifespan.

\section{Language Processing in Bilinguals}

\section{Joint activation of languages}

A logical possibility for the organization of a bilingual mind is that it consists of two independently-represented language systems that are uniquely accessed in response to the context: A fluent French-English bilingual ordering coffee in a Parisian café has no reason to consider how to form the request in English, and a Cantonese-English bilingual studying psychology in Boston does not need to recast the material through Chinese. Yet, substantial evidence shows that this is not how the bilingual mind is organized. Instead, fluent bilinguals show some measure of activation of both languages and some interaction between them at all times, even in contexts that are entirely driven by only one of the languages.

The evidence for this conclusion comes from psycholinguistic studies using such tasks as cross-language priming (in which a word in one language facilitates retrieval of a semantically related word in the other language) and lexical decision (in which participants decide whether a string of letters is a legal word in one of the languages) that show the influence of the currently unused language for both comprehension and production of speech [46-52]. Further evidence comes from patient studies showing intrusions from the irrelevant language or inappropriate language switches [53], and imaging studies indicating involvement of the non-target language while performing a linguistic task in the selected language [54-56]. Using eye-tracking technology, for example, Marian, Spivey, and Hirsch [57] reported that English-Russian bilinguals performing a task in English in which they had to look at the named picture from four alternatives were distracted by a picture whose name shared phonology with Russian even though there was no connection to the meaning of the target picture and no contextual cues indicating that Russian was relevant. Similarly, Thierry and $\mathrm{Wu}$ [58] presented English monolinguals, Chinese-English bilinguals, and Chinese monolinguals with pairs of words in English (translated to Chinese for Chinese monolinguals) and asked participants to decide if the words were semantically related or not. The manipulation was that half of the pairs contained a repeated character in the written Chinese forms, even though that orthographic feature was unrelated to the English meaning. Waveforms derived from analyses of electroencephalography (EEG) are used to indicate the neuronal response to language on a millisecond by millisecond scale. This event-related potential (ERP) signals the effort associated with integrating the meaning of words in a negative waveform about 400 milliseconds after the stimulus, a waveform called the $\mathrm{N} 400$. The more similar the words are to each other, the smaller is the amplitude of the N400. In the study by Thierry and $\mathrm{Wu}$, semantic relatedness was associated with significantly smaller N400 amplitude in all groups as expected, but the repeated character also led to smaller N400 for the two Chinese groups. Thus, although irrelevant to the task, participants were accessing the Chinese forms when making judgments about the semantic relation between English words. Subsequent research has refined these results by showing their basis in the phonology rather than the orthography of spoken language [59] and extended the phenomenon to the phonological hand forms of American Sign Language [60].

This joint activation is the most likely mechanisms for understanding the consequences of bilingualism for both linguistic and nonlinguistic processing. For linguistic processing, joint activation creates an attention problem that does not exist for monolinguals: In addition to selection constraints on such dimensions as register, collocation, and synonymy, the bilingual speaker also has to select the correct language from competing options. Although joint activation creates a risk for language interference and language errors, these rarely occur, indicating that the selection of the target language occurs with great accuracy. 
However, this need to select at the level of language system makes ordinary linguistic processing more effortful for bilinguals than monolinguals and explains some of the costs in psycholinguistic studies described above. For nonlinguistic processing, the need to resolve competition and direct attention is primarily the responsibility of general cognitive systems, in particular executive functions. The possible influence of linguistic processes on nonlinguistic executive control has enormous consequences for lifespan cognition and is discussed in the next section.

\section{Consequences of joint activation}

An appealing suggestion for how the executive control system achieves linguistic selection in the context of joint activation is through inhibition of the non-target language. At least two influential models have been proposed that place inhibition at the center of this selection. The first, the Inhibitory Control model [61] is based on the Supervisory Attentional System [62] and extends a domain-general and resource-limited attention system to the management of competing languages. The second, the Bilingual Interactive Activation Model (BIA+) [63], uses computer simulation to model lexical selection from both intralingual and extralingual competitors. Although both models assign a primary role to inhibition, they are quite different from each other and address a different aspect of the selection problem. It is useful, therefore, to consider the distinction between global inhibition and local inhibition proposed by De Groot and Christoffels [64]. Global inhibition refers to suppression of an entire language system, as in inhibiting French when speaking English, and local inhibition refers to inhibition of a specific competing distractor, such as the translation equivalent of the required concept. Both processes are required for fluent language selection but the two are carried out differently. Guo, Liu, Misra, and Kroll [65] used functional magnetic resonance imaging (fMRI) to demonstrate the recruitment of different systems for each of global inhibition (dorsal left frontal gyrus and parietal cortex) and local inhibition (dorsal anterior cingulate cortex, supplementary motor area) in a sample of Chinese-English bilinguals, and validated their distinct roles in bilingual language control. While Green's inhibitory control model is consistent with both types of inhibition, Dijkstra's BIA+ modeling item selection in local inhibition.

These types of inhibition also differ in their primary domain of influence, with local inhibition largely affecting linguistic performance and global inhibition affecting both linguistic and cognitive performance. The linguistic outcomes of inhibition are reduced speed and fluency of lexical access for bilinguals as described above. However, performance also requires a selection bias towards the target language, showing a role for activation [66, 67] as well as inhibition. These alternatives are not mutually exclusive but indicate the need for a more complete description of how attention is managed in bilingual language processing. Ultimately the degree of both inhibition and activation are relative rather than absolute and will be modulated by contextual, linguistic, and cognitive factors. The cognitive outcomes of linguistic inhibition are enhanced attentional control and will be described more fully in the next section. Importantly, the cognitive and linguistic outcomes are related. Three studies have reported a relationship between inhibition and ability in verbal and nonverbal tasks by showing a correlation between Stroop task performance and competing word selection [68], Simon task performance and language switching in picture naming [69], and cross-language interference and a variety of executive control measures [70]. Such results point to an extensive reorganization of cognitive and linguistic processes in bilinguals. 


\section{Cognitive networks in bilinguals}

\section{Bilingual performance on conflict tasks}

Early evidence that bilingual children solved nonverbal conflict tasks differently from monolingual children was reported in a study by Bialystok and Majumder [21]. Eight-yearold children were given a variety of nonverbal problems to solve, some of which contained perceptual distraction (block design from the Wechsler Intelligence Scale for Children (WISC) [71] and some which did not (Noelting's Juice Task [72, 73]). Bilingual children outperformed monolinguals on the conflict tasks, but children in the two groups were comparable on tasks that did not include distracting perceptual information. This pattern has been confirmed in studies of both children and adults using a flanker task (children: [74, 75]), theory of mind task (children: [76, 77]; adults: [78]), Simon task (children: [79]; adults: [44]). Other studies with adults have shown better performance by bilinguals in naming the font color in a Stroop task [25], smaller costs in task switching [80], better ability to maintain task set in an attention task [81], and more susceptibility to negative priming, presumably because of greater inhibition [82].

Some studies have extended these bilingual advantages into older age. Bialystok, Craik, Klein and Viswanathan [44] reported an experiment in which middle-aged and older adults who were either monolingual or bilingual were given a version of the Simon task.

Participants were shown either a green or a red square on each trial, and the task was to press an associated response key as rapidly as possible. The keys were located at each side of the presentation screen. In one condition, the squares appeared centrally on the screen, so there was no spatial conflict between the location of stimuli and responses; in this condition there were no reaction-time (RT) differences between language groups. In a second condition, the colored squares appeared laterally on the screen, either directly above the appropriate response key (congruent condition) or on the other side of the screen, above the incorrect response key (incongruent condition). The RT difference between congruent and incongruent response trials (the Simon effect) is a measure of attentional control. Bilinguals produced smaller Simon effects than monolinguals at all ages.

Three other results from this study are noteworthy. First, the decrease in attentional control in older adults was reduced in the bilingual groups, suggesting that bilingualism may be protective against the effects of cognitive aging. Second, whereas a bilingual advantage was expected for incongruent stimuli, it was also found for congruent stimuli. This result has been replicated in subsequent studies [43] and is difficult to account for in terms of response conflict or inhibition. Third, prolonged practice reduced both the Simon effect and the size of the bilingual advantage. Apparently all participants can learn to disregard the distracting effects of interfering stimuli given sufficient practice on a task, but it seems that bilinguals can learn this type of inhibition more rapidly. One interesting question in this regard is the extent to which this attenuation of attentional control is specific to the practiced situation, or whether it generalizes to tasks tapping attentional control in a different manner. Our conjecture is that the attenuation effect is context specific.

A complication that has emerged as more results are reported is that the bilingual advantage is not always found in samples of young adults. For example, a study examining performance on the Simon task in 5-year-olds, young, middle-aged and older adults found a bilingual advantage in RT in the 5-year-olds and in the older adults, but not in the young adult group [83]. Similarly, a study of the Stroop effect in younger and older adults found a bilingual advantage in both age groups but when the same participants performed the Simon arrow task the bilingual advantage was found only in the older adults [25]. Similarly, Salvatierra and Rosselli [45] used a simple version of the Simon task and reported a bilingual advantage for older but not younger adults. There is thus some evidence that the 
bilingual advantage is greatest in children and in older adults, but less constantly present in young adults - perhaps because the young adult group is at the developmentally peak age for cognitive control.

It appears that bilingual advantages for young adults tend to emerge on tasks or conditions that are difficult. For example, Bialystok [84] found that bilingual young adults outperformed their monolingual counterparts on the directional arrow Simon task, but only on the condition that included more monitoring and switching than a simpler condition. Similarly, several studies by Costa and colleagues have reported a bilingual advantage in young adults [75, 85, 86] but only under some conditions. For example, Costa et al. [85] demonstrated that the bilingual advantage on a flanker task held only under high monitoring conditions. In versions where most of the trials were of one type (congruent or incongruent) no bilingual advantage was observed; the advantage was found, however, in a condition involving 25\% incongruent and $75 \%$ congruent trials, although even there the advantage decreased over blocks of the experiment (cf., [44]). Costa et al. [85] concluded that the bilingual advantage reflects a more efficient monitoring system for conflict resolution, in that bilinguals may be better at determining when the misleading information can be safely ignored. Finally, Hernández et al. [86] used a nonlinguistic version of the Stroop effect and found a trend towards both reduced interference and enhanced facilitation in young adult bilinguals compared with monolinguals (cf., older participants in [25]). One interesting aspect of the studies by Costa, Hernández and colleagues is that the monolinguals were Spanish speakers and the bilinguals' two languages were Catalan and Spanish. Most of the participants were undergraduate students and were not immigrants, so the two groups were well equated apart from the language difference. In summary, the evidence for a bilingual advantage in younger adults is more sporadic than in other age groups, although at all ages there are some reports of studies showing no difference between monolinguals and bilinguals performing a conflict task.

\section{Neural correlates of cognitive reorganization}

Recently, studies have begun to investigate the neural correlates of bilingual processing examined in the behavioral research. The majority of this research has used fMRI to study bilinguals performing a linguistic task in their two languages. Typically, participants name pictures or generate words in response to a cue signaling the required language and performance is compared for single language and mixed language conditions. Two early studies revealed promising results. The first led to the surprising finding that language switching was accompanied by activation in the dorsolateral prefrontal cortex (DLPFC), an area known to be part of the general executive control system [28]. Less surprising was a study showing the involvement of Broca's area as well as a left frontal area in a language switching task [87]. Subsequent research has corroborated the involvement of these systems and shown that language switching elicits a spatially-distributed activation pattern involving bilateral frontal regions, bilateral precentral areas, bilateral caudate, bilateral (or midline) pre-supplementary areas (pre-SMA), and bilateral temporal regions. This pattern has been found for German-French bilinguals [88], Spanish-Catalan bilinguals [89], Chinese-English bilinguals [65, 90, 91] and Spanish-English bilinguals [92]. A few studies [65, 88] have also reported activation in anterior cingulate cortex (ACC), but activation in this area is not consistently observed. Abutalebi and colleagues [93] extended this finding to show activation of ACC for both language switching and nonverbal switching. Importantly, these studies confirm that frontal systems involved in executive control are recruited by bilinguals to manage attention to language.

Abutalebi and Green [94] conducted a qualitative review of these studies and proposed that the ACC, left prefrontal cortex, left caudate and bilateral supramarginal gyri (SMG) constitute the neural correlates of the control mechanism for bilingual language production. 
This model was confirmed in a quantitative meta-analysis examining bilingual language switching [95] (Figure 1). Both the qualitative and quantitative analyses point to multiple cortical regions in which functional activity is altered by bilingualism, but an outstanding question is whether activity in these regions is synchronous, forming a neural network that is responsive to bilinguals' experience of managing two languages. To this end, a study by Nakamura and colleagues [96] showed strong connectivity between left inferior frontal gyrus (IFG) and left middle temporal gyrus (MTG) in a group of Japanese-English bilinguals performing a cross-language priming task. The connectivity was stronger in the frontal-temporal coupling than in the reverse direction. This pattern was replicated using transcranial magnetic stimulation (TMS) with Japanese-English bilingual participants performing the same cross-language priming task. Nakamura and colleagues [96] interpreted the results as indicating top-down control from left IFG to left MTG in a bilingual context.

Taken together, fMRI research on bilingual language switching has implicated distributed cortical activation that converges in the frontal regions. Intriguingly, the brain regions related to bilingual switching are also critical for general attention and cognitive control [97, 98]. This overlap in brain regions activated for bilingual switching and cognitive control implies that the same mechanisms may be involved in both activities, and that these shared processes might help to explain the superior performance of bilinguals on nonverbal conflict tasks. In other words, using these cognitive control networks for bilingual language processing may reconfigure them for other purposes, providing part of the explanation for the behavioral differences between monolinguals and bilinguals found in nonverbal conflict tasks. Specifically, the evidence suggests that cognitive control networks may be more broadly based in bilinguals as a result of their dual function. However, fMRI studies on language switching in bilinguals can only show that these networks are included in bilingual language selection. Determining whether or not such reconfiguration occurs can only be evaluated by comparing monolinguals and bilinguals performing nonverbal conflict tasks. The hypothesis is that monolinguals and bilinguals will perform nonverbal control problems using somewhat different networks, specifically, that the network used by bilinguals will be more broadly based.

Only a few studies have contrasted the neural correlates of non-linguistic cognitive control in bilinguals and monolinguals. Garbin and colleagues [99] gave a color-shape switching task to Spanish monolingual and Spanish-Catalan bilingual young adults in fMRI. A bivalent stimulus (e.g., a red circle) and a cue (e.g., "color" or "shape") were shown, and participants responded to the indicated dimension. Both RT of switch costs and accuracy favored the bilingual participants but activation patterns were also different for the two groups: monolinguals showed increased activation in the right IFG, whereas bilinguals showed increased activation in left inferior frontal gyrus. More interestingly, higher levels of activation in left IFG and left striatum were associated with smaller switch costs for the bilingual participants, but increased activation in the right IFG was associated with larger switch costs. In light of the lack of switching effect in the behavioral data, it is possible that the bilinguals relied more on the left IFG and striatum in face of the demand to switch between responses associated with a bivalent stimulus. The left IFG was identified in both the qualitative [94] and quantitative [95] meta-analyses of bilingual language switching. This region is central to speech production [100] and has been shown to have higher activation for bilinguals than monolinguals during speech production [101, 102]. Thus, left IFG appears to be one of the overlapping brain regions in bilinguals handling both language switching and non-linguistic cognitive control.

A study by Luk and colleagues [103] used an adaptation of a flanker task to compare activation in monolingual and bilingual participants. The stimuli consisted of a string of five chevrons, and the task was to indicate the direction of the red one (that could appear in one 
of three positions) while ignoring the four black ones. In a previous behavioral study with these stimuli, bilinguals performed this task more rapidly than monolinguals [104]. The fMRI data were analyzed using a multivariate statistical technique for neuroimaging data (Partial Least Squares; for review, see [105]) to identify integrated neural networks. The results showed that monolinguals and bilinguals recruited different neural networks for both congruent and incongruent trials. Another condition that tested 'no-go' responses indicated no difference between groups. Importantly, greater activity in the bilingual network, including areas identified in the meta-analysis [95], was related to smaller RT costs for incongruent trials. There are two implications of these results. First, bilingualism alters functional neural network at the response-selection level (congruent and incongruent trials), but not at the motor execution level (response inhibition no-go trials), a pattern consistent with previous results for both adults [106] and children [79,107]. Second, bilinguals showed a brain-behavior correlation when suppressing interference from conflicting flankers, replicating a previous study using magnetoencephalography (MEG) [108].

Although bilingualism is a language experience, managing attention to two languages imposes demands on the cognitive system that require brain regions not typically used for language processing. From studies of bilingual language switching and non-linguistic cognitive control, and from the meta-analysis cited earlier, it seems likely that the neural locus of cognitive control in bilinguals lies in bilateral frontal regions. In order to facilitate information transfer between the hemispheres, it is also possible that prolonged bilingual experience alters anatomical structures in addition to cortical functional networks. Cortical activity assessed by fMRI is limited to blood-oxygenated-level-dependent (BOLD) signal in the grey matter. However, when investigating domain-general neural changes (cognitive control) in response to domain-specific experience (bilingualism), it is important to use methods that allow not only the identification of functional networks but also their underlying anatomical structures $[109,110]$.

There is some evidence for the plasticity of cortical grey matter in response to bilingualism. Mechelli and colleagues [111] reported higher grey matter density in left inferior parietal regions in a group of Italian-English bilinguals relative to English monolinguals. Strikingly, proficiency in English, the second language, correlated positively with grey matter density in this region. A recent study has extended brain plasticity to white matter. Luk, Bialystok, Craik and Grady [112] (Figure 1) used diffusion tensor imaging (DTI) to measure restingstate functional connectivity in monolingual and bilingual older adults. The results showed higher white matter integrity in bilingual older adults, primarily in the corpus callosum connecting the two hemispheres but also extending to bilateral superior longitudinal fasciculi, right inferior frontal-occipital fasciculus and uncinate fasciculus. Identifying a seed close to the white matter voxels showing a group difference, Luk et al. conducted a resting-state functional connectivity analysis and showed that while both monolinguals and bilinguals had correlating brain activity with contralateral regions at rest, bilinguals had increased anterior-posterior connectivity. This evidence suggests that bilingualism is associated with better maintenance of white matter structures in the course of normal aging [113]. Similar DTI results have also been recently reported in bilingual children around the left inferior frontal-occipital fasciculus [114].

\section{Nature of the bilingual advantage}

Why might bilingualism be associated with an advantage in attentional control? The need to manage two jointly activated languages apparently leads to an enhancement of frontalposterior attentional control mechanisms with the consequence that other types of cognitive control are also enhanced. Inhibitory control was suggested as the relevant mechanism in early studies [44, 61] and continues to be endorsed by some researchers [51, 115]. One problem with this account, however, is the recurrent finding of a bilingual advantage in 
congruent trials (for which there is no conflict) as well as incongruent trials [44, 75]. Minimally, therefore, inhibition alone is insufficient to explain bilingual processing differences. The inhibition view is also challenged by evidence from preverbal infants who demonstrate early effects of bilingualism but for whom language inhibition is not a plausible explanation (Box 1).

An alternative to inhibition is to consider the demands imposed by a mixed set of congruent and incongruent trials: there is always some probability that the next display may be an incongruent trial. Thus, even on congruent trials the display must be evaluated before the participant commits to a response. Congruent responses will typically be faster than incongruent responses, but individuals with superior attentional control processes (e.g., bilinguals) will be able to carry out such evaluative decisions more rapidly and effectively. Therefore, a different account of the bilingual advantage is in terms of conflict monitoring $[43,85,86]$. Evidence supporting this view comes from situations in which monitoring demands are low - if the majority of trials are of one type only [84, 85], the potentially misleading information (spatial position in the Simon task, flanker items in the flanker paradigm) can be treated as a valid cue, even if the participant must respond in the direction opposite to that indicated by the cue. In such low-monitoring conditions the bilingual advantage is typically not found. More generally, Hernández, Costa, and Humphreys [116] argue for a bilingual advantage in the deployment of attention, enabling them to resist "capture" by irrelevant information; such differences in attentional control may be the consequence of superior conflict monitoring. Conflict monitoring and inhibition are not mutually exclusive: Although monitoring is consistent with evidence that pure blocks of congruent trials are performed equivalently by monolinguals and bilinguals [106, 117], an inhibition account is still required to explain evidence that pure blocks of incongruent trials are sometimes performed faster by bilinguals, notably by older adults for whom the task is more effortful [106].

Another problem with a pure inhibition account is that bilingual advantages are only found with some types of inhibition. The relevant distinction is captured by the contrast between the concepts of response inhibition and interference suppression $[79,118]$. In response inhibition, a univalent stimulus is associated with a prepotent response that must be overruled, such as say "day" to a picture of night or press "left" when the arrow points right. Bilinguals typically show no advantage in these situations [79, 107]. In interference suppression, a bivalent stimulus contains two cues, each associated with a different response, such as the word "red" written in blue ink, so attention must be selectively focused on the relevant cue. Bilinguals typically outperform monolinguals on these tasks [25]. The hallmark of univalent response inhibition tasks is that the correct response can be preprogrammed before the cuing stimulus appears (e.g., if sun appears I'll say 'night;' if the arrow points right I'll respond left). On bivalent tasks, in contrast, the nature of the interfering information is not revealed until the display appears; for example, in the Simon task the participant prepares to respond on the left if the stimulus is green, but cannot prepare to deal with possible competing information until the display is shown. Bilinguals are more efficient at dealing with this online interference, in much the same way as the picture of a horse presented to a French/English bilingual would evoke both 'horse' and 'cheval', one of which must be suppressed. In a sense, the bilingual must constantly maintain the set of 'respond in one language, suppress the other language' whenever the possibility of two languages exists (cf., global inhibition). Further, this set maintenance must coexist with processing the stimuli and responses of the language currently utilized in a fluent and appropriate manner (cf., local inhibition). Thus, language use for bilinguals involves interference suppression, and the online monitoring required in both nonverbal task switching and language selection is similar. 
The suggestion that bilinguals are particularly adept at maintaining the appropriate one of two (or more) relevant task goals or attentional sets in working memory has much in common with the notion of selection of wanted stimuli as opposed to inhibition of unwanted ones. The net effect is the same, but by this view the suppression of potentially interfering information is essentially a consequence of active selection of the relevant information, rather than a primary mechanism of direct inhibition. This view is consistent with that proposed by Colzato and colleagues [81] who concluded that the bilingual advantage is not due to the constant exercise of inhibition, but that learning to keep two languages separate leads to an improvement in selecting goal-relevant information from goal-irrelevant information.

The sum of the evidence places the bilingual advantage beyond the explanatory power of a single process, a simple neural network, or a single executive control component. Instead, the ongoing experience of monitoring two languages, in conjunction with the need to monitor context, speaker, and other environmental cues while inhibiting attention to the currently unused but active language modifies how the mind and brain engage in ordinary conversation for bilinguals. The more effortful any of these components become, the more likely it is for bilingual advantages to emerge on nonverbal tasks. However, the impact of this modification may be seen most clearly on tasks that bear the closest resemblance to bilingual language use, such as task switching. In this case, it is easy to see how the task of attending to the shape of a stimulus instead of its color resembles the task of retrieving the name for an object in French instead of in English. Not surprisingly, these tasks are typically performed better by bilinguals than by monolinguals, although the details of those performances are not yet well understood: Some studies report bilingual advantages on mixing costs indicating set shifting $[86,106]$ while others report the advantage in local switch costs indicating response switching [80,119]. More generally, it is important to point out that bilingual advantages are not always found, even on tasks for which such performance differences would be expected. Some of the conditions that support the appearance of a bilingual advantage have been discussed, such as the need for monitoring and difficulty of the conditions, but others are still unknown. Another factor in determining performance outcomes is likely the nature or degree of bilingualism in the participants (Box 2). More details about the specific tasks and precise language histories of the bilingual participants may resolve these differences.

\section{Bilingualism and Dementia}

The finding that bilingualism enhances cognitive control raises the possibility that lifelong bilingualism protects against age-related cognitive decline, and may even postpone the onset of symptoms of dementia. In this case, bilingualism may be one of the environmental factors that contribute to cognitive reserve or brain reserve [120]. Cognitive reserve is the idea that engagement in stimulating physical or mental activity can act to maintain cognitive functioning in healthy aging and postpone the onset of symptoms in those suffering from dementia. These factors include education, occupational status, higher socio-economic class, and the continuing involvement in physical, intellectual and social activities [121-123]. If bilingualism contributes to cognitive reserve, then bilinguals should maintain higher levels of cognitive functioning and cope better with symptoms of dementia than monolinguals who are otherwise equivalent.

To test this idea, Bialystok, Craik, and Freedman [124] examined the hospital records of monolingual and bilingual patients who had been diagnosed with various types of dementia. In spite of being equivalent on a variety of cognitive and other factors, the bilinguals experienced onset symptoms and were diagnosed approximately $3-4$ years later than the monolinguals. Specifically, monolingual patients were diagnosed on average at age 75.4 
years, and bilinguals at age 78.6. A replication from a new set of patients all diagnosed with probable Alzheimer's disease (AD) [125] confirmed the results.

Three questions about these results are their reliability, validity, and causality. For reliability, several studies have replicated these findings. Chertkow et al. [126] reported partial support for the original results and showed that multilinguals were diagnosed with $\mathrm{AD}$ later than comparable monolinguals, although a more limited effect was found when monolinguals were compared with bilinguals. A similar positive relationship between multilingualism and high-level cognitive functioning was reported by Kavé et al. [127] in a study of elderly Israelis. Gollan et al. [128] reported a study with Spanish-English bilinguals who had been diagnosed with probable $\mathrm{AD}$ and found that a higher degree of bilingualism was associated with later age of onset and diagnosis, although only in the less-educated patients.

Second, validity requires demonstrating the specific relation between the predictor and outcome variables. Previously, socioeconomic status, cultural differences and immigration status have been suggested as contributors to or even causes of the bilingual advantage. However, in both Toronto studies, educational level and occupational status favored the monolingual group and immigration status was ruled out as a contributing factor.

Third, regarding cause and effect, is it possible the people that people with 'good brains' are both resistant to dementia and also more likely to learn a second language? This is unlikely: most people do not become bilingual because they are bright or have a flair for learning languages, but rather out of necessity. Supporting this interpretation, a recent study showed that in a sample of monolingual and bilingual AD patients matched on age, cognitive level, and other factors, CT scans showed more AD pathology in the brains of the bilinguals, consistent with the idea that they are better able to cope with the disease and can function longer without showing symptoms [129].

\section{Conclusion}

In the first study reporting the surprising outcome of an advantage in cognitive and linguistic performance by bilingual children, Peal and Lambert [13] concluded: "Intellectually [the bilingual child's] experience with two language systems seems to have left him with a mental flexibility, a superiority in concept formation, a more diversified set of mental abilities" (p. 20). Peal and Lambert did not explain what they meant by "mental flexibility" but the description works well to describe the data accumulated in the 50 years since their original study. Bilinguals do sometimes have an advantage in inhibition, but they also have an advantage in selection; bilinguals do sometimes have an advantage in switching, but they also have an advantage in sustaining attention; and bilinguals do sometimes have an advantage in working memory, but they also have an advantage in representation and retrieval. Together, this pattern sounds like "mental flexibility", the ability to adapt to ongoing changes and process information efficiently and adaptively.

It should not be surprising that intense and sustained experience leaves its mark on our minds and brains - the functional connections that come from practice are surely changed by massive experience, and the structural regions that are recruited for specific activities undoubtedly change as well through use. These responses to experience are precisely what we mean by neuroplasticity. Yet, in the case of bilingualism, the assumption has long been that any such effects would be deeply negative: As one influential educational researcher commented in 1926, "This might be considered evidence that the use of a foreign language in the home is one of the chief factors in producing mental retardation as measured by intelligence tests" ([130], p. 393). Almost a century later, and in the face of substantial 
evidence to the contrary, there remains resistance to the idea that bilingualism can enhance aspects of cognitive function. Educational and clinical practitioners routinely advise parents to "simplicify" their children's linguistic environment when there are signs of academic struggle, and language professionals prescribe optimal timetables (and methods) for introducing languages to children to minimize the inevitable confusion. But such views are based on fear and anecdote - the weight of scientific evidence supports the promise of "mental flexibility". There is still much we do not know about the effect of bilingualism on the mind, the neural correlates of those effects, and the causal components of the experience that lead to them. But it is too late to turn back: it is now clear that the bilingual mind has been uniquely shaped by experience.

\section{Box 1: Bilingualism in infancy}

Research with infants being raised in bilingual homes has produced dramatic evidence for very early effects of bilingualism and challenges some standard explanations for the mechanism underlying these effects. It has long been known that children being raised with two languages do not confuse the languages when learning to speak, even though they may borrow from one when speaking the other [131]. It is also well known that monolingual infants lose the ability to make phonetic discriminations not present in their language by about 10-months old whereas bilingual infants continue to distinguish between phonetic categories relevant to all languages. Thus, it is not surprising that bilingual infants can differentiate between their two languages essentially from birth [132]. What is surprising, however, is the extension of this discrimination to non-acoustic properties of language. Weikum and colleagues [133] showed silent video clips to 8month old infants who were being raised in homes that were either monolingual English or English-French bilingual. Using a habituation paradigm, the speaker switched languages after habituation and the researchers measured whether or not infants regained interest. The results showed renewed attention among the bilingual but not the monolingual infants. To determine whether the bilingual infants had learned about the facial structures that accompany each language or something more general, the same materials were presented to monolingual Spanish (or Catalan) infants and bilingual Spanish-Catalan infants [134]. Again, only the bilingual infants noticed the change in language, even though the children in this study had no experience with either language. The authors concluded that bilingualism enhances general perceptual attentiveness through the experience of attending to two sets of visual cues.

This enhanced perceptual attentiveness may help explain the results of a study in which 7-month old monolingual and bilingual infants learned a head-turn response to a cue to obtain a visual reward and then had to replace that with a competing response for the same reward [135]. Again, only the bilingual infants could learn the new response. Even before children have productive language ability, the experience of building two distinct representational systems endows them with greater perceptual and attentional resources than their monolingual peers. In light of such evidence for bilingual advantages in the first year of life, explanations for the mechanism responsible for the advantages found later may need to be reconsidered to include a role for such perceptual processes.

\section{Box 2: How bilingual?}

Bilingualism is not a categorical experience but experimental research designs require it is treated as such - participants are monolingual or bilingual and differences in performance are assessed for members of the two groups. However, individuals can never be perfectly monolingual or bilingual: even the most monolingual people have had some experience with another language, for example as a school subject or a travel 
necessity, and all bilinguals have preferred languages or preferred contexts for each. These gradations raise three questions about the research results.

The first question is the possibility of a cumulative benefit for multiple languages. If managing two languages enhances cognitive control processes, then does further enhancement accrue from the management of three or more languages, as explicitly proposed by Diamond [136]? Research by Chertkow et al. [123] on Alzheimer's disease and Kavé et al. [127] on normal aging showed better outcomes for multilinguals than for bilinguals, but there may be significant differences between multilinguals and bilinguals that do not exist between bilinguals and monolinguals. As we have suggested, bilinguals are typically not pre-selected for talent or interest but multilinguals may often be individuals with high ability and motivation to learn other languages, factors which may impact as well on cognitive performance.

The second question is the degree of bilingualism required for these benefits to emerge. If bilingualism is protective against some forms of dementia, then middle-aged people will want to know whether it is too late to learn another language, or whether their highschool French will count towards cognitive reserve. A related question concerns the age of acquisition of a second language; is earlier better? The best answer at present is that early age of acquisition, overall fluency, frequency of use, levels of literacy and grammatical accuracy all contribute to the bilingual advantage, with no single factor being decisive [137, 138]. Increasing bilingualism leads to increasing modification of cognitive outcomes.

Finally, if the benefits of bilingualism are at least partly explained by the joint activation of two languages, does the similarity of the two languages matter? Does Spanish-English bilingualism require more (or less?) attentional control to maintain separation than say Chinese-English bilingualism? In a study with children who spoke English plus one of French, Spanish, or Chinese, there was no effect of the type of bilingualism, and all bilingual children outperformed monolingual children on tests of executive control [139].

\section{Box 3: Outstanding questions}

1. Nature of the Bilingual Advantage: What are the limits and boundary conditions for the bilingual advantage and why are bilingual advantages not always found? What is the role of the standard components of executive control - inhibition, shifting, and working memory - in bilingual differences in processing? Do these relations change over the lifespan?

2. Cognitive Reserve: Is the bilingual protection against cognitive decline similar to other types of cognitive reserve in terms of mechanism and neural correlates?

3. Brain Correlates: What changes occur in the frontal lobes? Are there effects on other brain regions? What is the mechanism for these experience-dependent changes in frontal networks?

4. Psychopathology: What are the neural correlates of the protective effects for patients with dementia? Does bilingualism have differential effects on various types of dementia?

\section{Acknowledgments}

Preparation of this manuscript was supported by grant R01HD052523 from the US National Institutes of Health and grant A2559 from the Natural Sciences and Engineering Research Council of Canada to EB, grant A8261 from the Natural Sciences and Engineering Research Council of Canada to FIMC, and grant MOP57842 from the Canadian 
Institutes of Health Research to EB and FIMC. We thank Steven Lovasz for his assistance in preparing the manuscript.

\section{References}

1. Grosjean, F. Bilingual: life and reality. Harvard University Press; 2010.

2. U. S. Census Bureau. [Retrieved August 4, 2011] The 2011 Statistical Abstract. Languages Spoken At Home by Language: 2008, Table 53. 2010. from http://www.census.gov/compendia/statab/cats/population/ancestry_language_spoken_at_home.html

3. Statistics Canada. [Retrieved August 4, 2011] 2006 Census of Canada highlight tables: Population by language spoken most often at home and age groups, 2006 counts, for Canada, provinces and territories - 20\% sample data. 2007. (Catalogue number 97-555-XWE2006002). from http://www12.statcan.ca/census-recensement/2006/dp-pd/hlt/97-555/T402-eng.cfm? Lang $=\mathrm{E} \& \mathrm{~T}=402 \& \mathrm{GH}=4 \& \mathrm{SC}=1 \& \mathrm{~S}=99 \& \mathrm{O}=\mathrm{A}$

4. U. S. Census Bureau. [Retrieved August 4, 2011] The 2011 Statistical Abstract. Language Spoken at Home--Cities With 100,000 Persons or More: 2008, Table 55. 2010. from http://www.census.gov/compendia/statab/cats/population/ancestry_language_spoken_at_home.html

5. European Commission. [Retrieved November 1, 2011] "Special Eurobarometer 243: Europeans and their Languages (Executive Summary)" (PDF); Europa web portal. 2006. p. 3from http://ec.europa.eu/public_opinion/archives/ebs/ebs_243_sum_en.pdf

6. Draganski B, et al. Neuroplasticity: changes in grey matter induced by training. Nature. 2004; 427:311-312. [PubMed: 14737157]

7. Green CS, Bavelier D. Exercising your brain: a review of human brain plasticity and training induced learning. Psychol. Aging. 2008; 23:692-701. [PubMed: 19140641]

8. Salthouse TA, Mitchell DRD. Effects of age and naturally occurring experience on spatial visualization performance. Dev. Psychol. 1990; 26:845-854.

9. Maguire EA, et al. Navigation-related structural change in the hippocampi of taxi drivers. Proc. Natl. Acad. Sci. U. S. A. 2000; 97:4398-4403. [PubMed: 10716738]

10. Elbert T, et al. Increased cortical representation of fingers of the left hand in string players. Science. 1995; 270:305-307. [PubMed: 7569982]

11. Schellenberg EG. Music lessons enhance IQ. Psychol. Sci. 2004; 15:511-514. [PubMed: 15270994]

12. Hakuta, K. Mirror of language: the debate on bilingualism. New York: Basic Books; 1986.

13. Peal E, Lambert W. The relation of bilingualism to intelligence. Psychol. Monogr. 1962; 76:1-23.

14. Ben-Zeev S. The influence of bilingualism on cognitive strategy and cognitive development. Child Dev. 1977; 48:1009-1018.

15. Bialystok E. Factors in the growth of linguistic awareness. Child Dev. 1986; 57:498-510.

16. Bialystok E. Levels of bilingualism and levels of linguistic awareness. Dev. Psychol. 1988; 24:560-567.

17. Cromdal J. Childhood bilingualism and metalinguistic skills: analysis and control in young Swedish-English bilinguals. Appl. Psycholinguist. 1999; 20:1-20.

18. Galambos SJ, Goldin-Meadow S. The effects of learning two languages on levels of metalinguistic awareness. Cognition. 1990; 34:1-56. [PubMed: 2302940]

19. Galambos SJ, Hakuta K. Subject-specific and task-specific characteristics of metalinguistic awareness in bilingual children. Appl. Psycholinguist. 1988; 9:141-162.

20. Ianco-Worrall A. Bilingualism and cognitive development. Child Dev. 1972; 43:1390-1400.

21. Bialystok E, Majumder S. The relationship between bilingualism and the development of cognitive processes in problem-solving. Appl. Psycholinguist. 1998; 19:69-85.

22. Mezzacappa E. Alerting, orienting, and executive attention: developmental properties and sociodemographic correlates in an epidemiological sample of young, urban children. Child Dev. 2004; 75:1373-1386. [PubMed: 15369520]

23. Bialystok E, et al. Receptive vocabulary differences in monolingual and bilingual children. Bilingualism: Language and Cognition. 2010; 13:525-531. 
24. Bialystok E, Luk G. Receptive vocabulary differences in monolingual and bilingual adults. Bilingualism: Language and Cognition. 2011

25. Bialystok E, et al. Lexical access in bilinguals: effects of vocabulary size and executive control. J. Neurolinguistics. 2008; 21:522-538.

26. Costa A, Santesteban M. Lexical access in bilingual speech production: evidence from language switching in highly proficient bilinguals and L2 learners. J. Mem. Lang. 2004; 50:491-511.

27. Gollan TH, et al. Bilingualism affects picture naming but not picture classification. Mem. Cognit. $2005 ; 33: 1220-1234$.

28. Hernandez, et al. In search of the language switch: an fMRI study of picture naming in SpanishEnglish bilinguals. Brain Lang. 2000; 73:421-431. [PubMed: 10860563]

29. Gollan TH, et al. The bilingual effect on Boston Naming Test performance. J. Int. Neuropsychol. Soc. 2007; 13:197-208. [PubMed: 17286875]

30. Roberts PM, et al. English performance of proficient bilingual adults on the Boston Naming Test. Aphasiology. 2002; 16:635-645.

31. Ransdell SE, Fischler I. Memory in a monolingual mode: when are bilinguals at a disadvantage? J. Mem. Lang. 1987; 26:392-405.

32. Ivanova I, Costa A. Does bilingualism hamper lexical access in speech production? Acta Psychol. 2008; 127:277-288.

33. Bialystok E, et al. Cognitive control and lexical access in younger and older bilinguals. J. Exp. Psychol. Learn. Mem. Cogn. 2008; 34:859-873. [PubMed: 18605874]

34. Gollan TH, et al. Semantic and letter fluency in Spanish-English bilinguals. Neuropsychology. 2002; 16:562-576. [PubMed: 12382994]

35. Luo L, et al. Effect of language proficiency and executive control on verbal fluency performance in bilinguals. Cognition. 2010; 114:29-41. [PubMed: 19793584]

36. Portocarrero JS, et al. Vocabulary and verbal fluency of bilingual and monolingual college students. Arch. Clin. Neuropsychol. 2007; 22:415-422. [PubMed: 17336036]

37. Rosselli M, et al. Verbal fluency and repetition skills in healthy older Spanish-English bilinguals. Appl. Neuropsychol. 2000; 7:17-24. [PubMed: 10800624]

38. Gollan TH, Ferreira VS. Should I stay or should I switch? A cost-benefit analysis of voluntary language switching in young and aging bilinguals. J. Exp. Psychol. Learn. Mem. Cogn. 2009; 35:640-665. [PubMed: 19379041]

39. Miyake A, et al. The unity and diversity of executive functions and their contributions to complex "frontal lobe" tasks: a latent variable analysis. Cogn. Psychol. 2000; 41:49-100. [PubMed: 10945922]

40. Best JR, et al. Relations between executive function and academic achievement from ages 5 to 17 in a large, representative national sample. Learn. Individ. Differ. 2011; 21:327-336. [PubMed: 21845021]

41. Duncan GJ, et al. Early childhood poverty and adult attainment, behavior, and health. Child Dev. 2010; 81:306-325. [PubMed: 20331669]

42. Adesope OO, et al. A systematic review and meta-analysis of the cognitive correlates of bilingualism. Rev. Educ. Res. 2010; 80:207-245.

43. Hilchey MD, Klein RM. Are there bilingual advantages on nonlinguistic interference tasks? Implications for the plasticity of executive control processes. Psychon. Bull. Rev. 2011; 18:625658. [PubMed: 21674283]

44. Bialystok E, et al. Bilingualism, aging, and cognitive control: evidence from the Simon task. Psychol. Aging. 2004; 19:290-303. [PubMed: 15222822]

45. Salvatierra JL, Rosselli M. The effect of bilingualism and age on inhibitory control. Int. J. Bilingual. 2010; 15:26-37.

46. Beauvillain C, Grainger J. Accessing interlexical homographs: some limitations of a languageselective access. J. Mem. Lang. 1987; 26:658-672.

47. Colomé A. Lexical activation in bilinguals' speech production: language-specific or languageindependent? J. Mem. Lang. 2001; 45:721-736. 
48. Costa A, et al. Lexical selection in bilinguals: do words in the bilingual's lexicons compete for selection? J. Mem. Lang. 1999; 41:365-397.

49. Francis WS. Analogical transfer of problem solutions within and between languages in SpanishEnglish bilinguals. J. Mem. Lang. 1999; 40:301-329.

50. Hernandez AE, et al. Processing across the language boundary: a cross-modal priming study of Spanish-English bilinguals. J. Exp. Psychol. Learn. Mem. Cogn. 1996; 22:846-864. [PubMed: 8708603]

51. Kroll JF, et al. Language selection in bilingual speech: evidence for inhibitory processes. Acta Psychol. 2008; 128:416-430.

52. Kroll, JF.; de Groot, AMB. Lexical and conceptual memory in the bilingual: mapping form to meaning in two languages. In: de Groot, AMB.; Kroll, JF., editors. Tutorials in bilingualism. Erlbaum Press; 1997. p. 169-199.

53. Fabbro F, et al. Pathological switching between languages following frontal lesion in a bilingual patient. J. Neurol. Neurosurg. Psychiatry. 2000; 68:650-652. [PubMed: 10766900]

54. Martin CD, et al. Brain potentials reveal semantic priming in both the 'active' and the 'nonattended' language of early bilinguals. NeuroImage. 2009; 47:326-333. [PubMed: 19374949]

55. Rodriguez-Fornells A, et al. Brain potential and functional MRI evidence for how to handle two languages with one brain. Nature. 2002; 415:1026-1029. [PubMed: 11875570]

56. Kroll JF, et al. Language selectivity is the exception, not the rule: arguments against a fixed locus of language selection in bilingual speech. Bilingualism: Language and Cognition. 2006; 9:119135.

57. Marian V, et al. Shared and separate systems in bilingual language processing: converging evidence from eyetracking and brain imaging. Brain Lang. 2003; 86:70-82. [PubMed: 12821416]

58. Thierry G, Wu YJ. Brain potentials reveal unconscious translation during foreign language comprehension. Proc. Natl. Acad. Sci. U. S. A. 2007; 104:12530-12535. [PubMed: 17630288]

59. Wu YJ, Thierry G. Chinese-English bilinguals reading English hear Chinese. J. Neurosci. 2010; 30:7646-7651. [PubMed: 20519539]

60. Morford JP, et al. When deaf signers read English: do written words activate their sign translations? Cognition. 2011; 118:286-292. [PubMed: 21145047]

61. Green DW. Mental control of the bilingual lexico-semantic system. Bilingualism: Language and Cognition. 1998; 1:67-81.

62. Norman, DA.; Shallice, T. Attention to action: willed and automatic control of behavior. In: Davidson, RJ., et al., editors. Consciousness and self regulation. Advances in research and theory. Plenum Press; 1986. p. 1-18.

63. Dijkstra, A.; Van Heuven, WJB. The BIA model and bilingual word recognition. In: Grainger, J.; Jacobs, AM., editors. Localist connectionist approaches to human cognition. Erlbaum Press; 1998. p. 189-225.

64. de Groot AMB, Christoffels IK. Language control in bilinguals: monolingual tasks and simultaneous interpreting. Bilingualism: Language and Cognition. 2006; 9:189-201.

65. Guo T, et al. Local and global inhibition in bilingual word production: fMRI evidence from Chinese-English bilinguals. NeuroImage. 2011; 56:2300-2309. [PubMed: 21440072]

66. Costa, A. Lexical access in bilingual production. In: Kroll, JF.; de Groot, AMB., editors. Handbook of bilingualism: Psycholinguistic approaches. Oxford University Press; 2005. p. 308-325.

67. Costa A, et al. How do highly proficient bilinguals control their lexicalization process? Inhibitory and language specific selection mechanisms are both functional. J. Exp. Psychol. Learn. Mem. Cogn. 2006; 32:1057-1074. [PubMed: 16938046]

68. Blumenfeld HK, Marian V. Bilingualism influences inhibitory control in auditory comprehension. Cognition. 2011; 118:245-257. [PubMed: 21159332]

69. Linck JA, et al. Inhibitory control predicts language switching performance in trilingual speech production. Bilingualism: Language and Cognition. 2011

70. Festman J, et al. Individual differences in control of language interference in late bilinguals are mainly related to general executive abilities. Behav. Brain Funct. 2010 
71. Wechsler, D. Wechsler Intelligence Scale for Children, Revised. New York: Psychological Corporation; 1974.

72. Noelting G. The development of proportional reasoning and the ratio concept: part I differentiation of stages. Educ. Stud. Math. 1980; 11:217-253.

73. Noelting G. The development of proportional reasoning and the ratio concept: part II - problemstructure at successive stages: problem-solving strategies and the mechanism of adaptive restructuring. Educ. Stud. Math. 1980; 11:331-363.

74. Yang S, et al. Early childhood bilingualism leads to advances in executive attention: dissociating culture and language. Bilingualism: Language and Cognition. 2011; 14:412-422.

75. Costa A, et al. Bilingualism aids conflict resolution: evidence from the ANT task. Cognition. 2008; 106:59-86. [PubMed: 17275801]

76. Goetz P. The effects of bilingualism on theory of mind development. Bilingualism: Language and Cognition. 2003; 6:1-15.

77. Kovács AM. Early bilingualism enhances mechanisms of false-belief reasoning. Dev. Sci. 2009; 12:48-54. [PubMed: 19120412]

78. Rubio-Fernández P, Glucksberg S. Reasoning about other peoples beliefs: bilinguals have an advantage. J. Exp. Psychol. Learn. Mem. Cogn. 2012; 38:211-217. [PubMed: 21875251]

79. Martin-Rhee MM, Bialystok E. The development of two types of inhibitory control in monolingual and bilingual children. Bilingualism: Language and Cognition. 2008; 11:81-93.

80. Prior A, MacWhinney B. A bilingual advantage in task switching. Bilingualism: Language and Cognition. 2010; 13:253-262.

81. Colzato LS, et al. How does bilingualism improve executive control? A comparison of active and reactive inhibition mechanisms. J. Exp. Psychol. Learn. Mem. Cogn. 2008; 34:302-312. [PubMed: 18315407]

82. Treccani B, et al. Spatial negative priming in bilingualism. Psychon. Bull. Rev. 2009; 16:320-327. [PubMed: 19293101]

83. Bialystok E, et al. Bilingualism across the lifespan: the rise and fall of inhibitory control. Int. J. Bilingual. 2005; 9:103-119.

84. Bialystok E. Effect of bilingualism and computer video game experience on the Simon task. Can. J. Exp. Psychol. 2006; 60:68-79. [PubMed: 16615719]

85. Costa A, et al. On the bilingual advantage in conflict processing: now you see it, now you don't. Cognition. 2009; 113:135-149. [PubMed: 19729156]

86. Hernández M, et al. The impact of bilingualism on the executive control and orienting networks of attention. Bilingualism: Language and Cognition. 2010; 13:315-325.

87. Price CJ, et al. Functional imaging study of translation and language switching. Brain. 1999; 122:2221-2236. [PubMed: 10581218]

88. Abutalebi J, et al. Language control and lexical competition in bilinguals: an event-related fMRI study. Cereb. Cortex. 2008; 18:1496-1505. [PubMed: 17947346]

89. Garbin G, et al. Neural bases of language switching in high and early proficient bilinguals. Brain Lang. 2011; 119:129-135. [PubMed: 21550652]

90. Wang YP, et al. Neural bases of asymmetric language switching in second-language learners: an ER-fMRI study. NeuroImage. 2007; 35:862-870. [PubMed: 17324590]

91. Wang Y, et al. Sustained and transient language control in the bilingual brain. NeuroImage. 2009; 47:414-422. [PubMed: 19167507]

92. Hernandez AE. Language switching in the bilingual brain: what's next? Brain Lang. 2009; 109:133-140. [PubMed: 19250662]

93. Abutalebi J, et al. Bilingualism tunes the anterior cingulate cortex for conflict monitoring. Cereb. Cortex. 2011

94. Abutalebi J, Green DW. Control mechanisms in bilingual language production: neural evidence from language switching studies. Lang. Cogn. Process. 2008; 23:557-582.

95. Luk G, et al. Cognitive control for language switching in bilinguals: a quantitative meta-analysis of functional neuroimaging studies. Lang. Cogn. Process. 2011 
96. Nakamura K, et al. Neural control of cross-language asymmetry in the bilingual brain. Cereb. Cortex. 2010; 20:2244-2251. [PubMed: 20051357]

97. Hedden T, Gabrieli JDE. Shared and selective neural correlates of inhibition, facilitation, and shifting processes during executive control. NeuroImage. 2010; 51:421-431. [PubMed: 20123030]

98. Toro R, et al. Functional coactivation map of the human brain. Cereb. Cortex. 2008; 18:25532559. [PubMed: 18296434]

99. Garbin G, et al. Bridging language and attention: brain basis of the impact of bilingualism on cognitive control. NeuroImage. 2010; 53:1272-1278. [PubMed: 20558314]

100. Price CJ. The anatomy of language: a Review of 100 MRI studies published in 2009. Ann. N. Y. Acad. Sci. 2010; 1191:62-88. [PubMed: 20392276]

101. Parker Jones $\mathrm{O}$, et al. Where, when and why brain activation differs for bilinguals and monolinguals during picture naming and reading aloud. Cereb. Cortex. 2011

102. Simmonds AJ, et al. Two tongues, one brain: imaging bilingual speech production. Front. Psychol. 2011; 2:166. [PubMed: 21811481]

103. Luk G, et al. Distinct neural correlates for two types of inhibition in bilinguals: response inhibition versus interference suppression. Brain Cogn. 2010; 74:347-357. [PubMed: 20965635]

104. Emmorey K, et al. The source of enhanced cognitive control in bilinguals: evidence from bimodal bilinguals. Psychol. Sci. 2008; 19:1201-1206. [PubMed: 19121123]

105. Krishnan A, et al. Partial Least Squares (PLS) methods for neuroimaging: a tutorial and review. NeuroImage. 2011; 56:455-475. [PubMed: 20656037]

106. Bialystok E, et al. Executive control in a modified anti-saccade task: effects of aging and bilingualism. J. Exp. Psychol. Learn. Mem. Cogn. 2006; 32:1341-1354. [PubMed: 17087588]

107. Carlson SM, Meltzoff AN. Bilingual experience and executive functioning in young children. Dev. Sci. 2008; 11:282-298. [PubMed: 18333982]

108. Bialystok E, et al. Effect of bilingualism on cognitive control in the Simon task: evidence from MEG. NeuroImage. 2005; 24:40-49. [PubMed: 15588595]

109. Bressler SL, Menon V. Large-scale brain networks in cognition: emerging methods and principles. Trends Cogn. Sci. 2010; 14:277-290. [PubMed: 20493761]

110. Wig GS, et al. Concepts and principles in the analysis of brain networks. Ann. N. Y. Acad. Sci. 2011; 1224:126-146. [PubMed: 21486299]

111. Mechelli A, et al. Neurolinguistics: structural plasticity in the bilingual brain. Nature. 2004; 431:757. [PubMed: 15483594]

112. Luk G, et al. Lifelong bilingualism maintains white matter integrity in older adults. J. Neurosci. 2011; 31:16808-16813. [PubMed: 22090506]

113. Davis SW, et al. Assessing the effects of age on long white matter tracts using diffusion tensor tractography. NeuroImage. 2009; 46:530-541. [PubMed: 19385018]

114. Mohades SG, et al. DTI reveals structural differences in white matter tracts between bilingual and monolingual children. Brain Res. 2011

115. Philipp AM, Koch I. Inhibition in language switching: what is inhibited when switching between languages in naming tasks? J. Exp. Psychol. Learn. Mem. Cogn. 2009; 35:1187-1195. [PubMed: 19686014]

116. Hernández M, et al. Escaping capture: bilingualism modulates distraction from working memory. Cognition. 2012; 122:37-50. [PubMed: 21890125]

117. Bialystok E. Global-local and trail-making tasks by monolingual and bilingual children: beyond inhibition. Dev. Psychol. 2010; 46:93-105. [PubMed: 20053009]

118. Bunge SA, et al. Immature frontal lobe contributions to cognitive control in children: evidence from fMRI. Neuron. 2002; 33:301-311. [PubMed: 11804576]

119. Prior A, Gollan TH. Good language-switchers are good task-switchers: evidence from SpanishEnglish and Mandarin-English bilinguals. J. Int. Neuropsychol. Soc. 2011; 17:682-691.

120. Stern Y. What is cognitive reserve? Theory and research application of the reserve concept. J. Int. Neuropsychol. Soc. 2002; 8:448-460. [PubMed: 11939702]

121. Stern Y, et al. Influence of education and occupation on the incidence of Alzheimer's disease. JAMA. 1994; 271:1004-1010. [PubMed: 8139057] 
122. Bennett DA, et al. Education modifies the relation of AD pathology to level of cognitive function in older persons. Neurology. 2003; 60:1909-1915. [PubMed: 12821732]

123. Bennett DA, et al. The effect of social networks on the relation between Alzheimer's disease pathology and level of cognitive function in old people: a longitudinal cohort study. Lancet Neurol. 2006; 5:406-412. [PubMed: 16632311]

124. Bialystok E, et al. Bilingualism as a protection against the onset of symptoms of dementia. Neuropsychologia. 2007; 45:459-464. [PubMed: 17125807]

125. Craik FIM, et al. Delaying the onset of Alzheimer's disease: bilingualism as a form of cognitive reserve. Neurology. 2010; 75:1726-1729. [PubMed: 21060095]

126. Chertkow H, et al. Multilingualism (but not always bilingualism) delays the onset of Alzheimer's disease: evidence from a bilingual community. Alzheimer Dis. Assoc. Disord. 2010; 24:118-125. [PubMed: 20505429]

127. Kavé G, et al. Multilingualism and cognitive state in the oldest old. Psychol. Aging. 2008; 23:7078. [PubMed: 18361656]

128. Gollan TH, et al. Degree of bilingualism predicts age of diagnosis of Alzheimer's disease in loweducation but not in highly educated Hispanics. Neuropsychologia. 2011; 49:3826-3830. [PubMed: 22001315]

129. Schweizer TA, et al. Bilingualism as a contributor to cognitive reserve: evidence from brain atrophy in Alzheimer's disease. Cortex. 2011

130. Goodenough F. Racial differences in the intelligence of school children. J. Exp. Psychol. 1926; 9:388-397.

131. Genesee F. Early bilingual development: one language or two? J. Child Lang. 1989; 16:161-179. [PubMed: 2647777]

132. Byers-Heinlein K, et al. The roots of bilingualism in newborns. Psychol. Sci. 2010; 21:343-348. [PubMed: 20424066]

133. Weikum W, et al. Visual language discrimination in infancy. Science. 2007; 316:1159. [PubMed: 17525331]

134. Sebastián-Gallés N, et al. A bilingual advantage in visual language discrimination in infancy. Psychol. Sci. (in press).

135. Kovács ÁM, Mehler J. Cognitive gains in 7-month-old bilingual infants. Proc. Natl. Acad. Sci. U. S. A. 2009; 106:6556-6560. [PubMed: 19365071]

136. Diamond J. The benefits of multilingualism. Science. 2010; 330:332-333. [PubMed: 20947754]

137. Luk, G. Ph.D. dissertation. Canada: York University; 2008. The anatomy of the bilingual influence of cognition: Levels of functional use and proficiency of language. (Unpublished)

138. Luk G, et al. Is there a relation between onset age of bilingualism and enhancement of cognitive control? Bilingualism: Language and Cognition. 2011; 14:588-595.

139. Barac R, Bialystok E. Bilingual effects on cognitive and linguistic development: role of language, cultural background, and education. Child Dev. 2012 


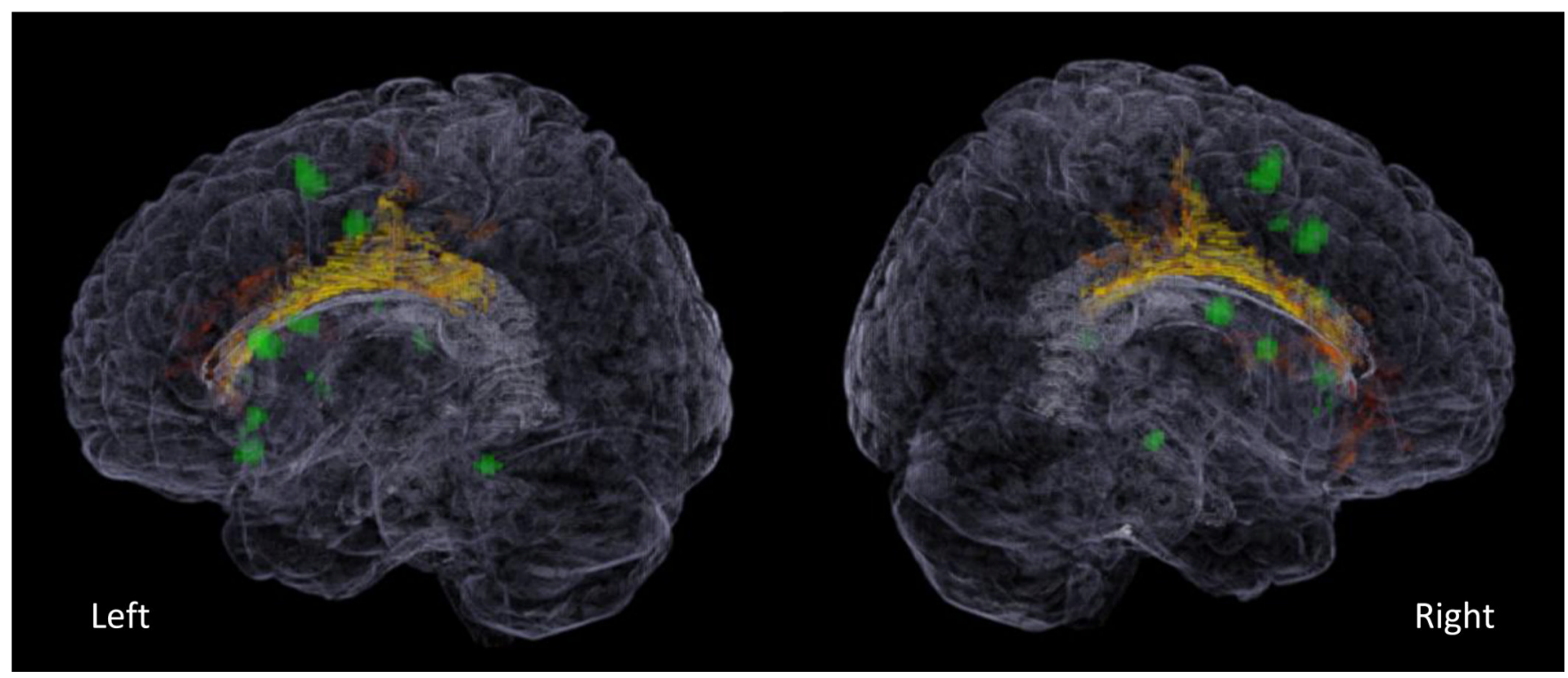

Figure 1.

Bilingual influence on brain function and structure. Transparent brains showing the left and right hemispheres. Green voxels depict grey matter regions showing high activation during bilingual language switching in a meta-analysis (94). Red-yellow voxels indicate regions of higher white matter integrity in bilingual older adults relative to monolinguals (111).

Together, the functional and structural data indicate that neural correlates of bilingualism are observed in the frontal lobes, generally responsible for higher cognition such as executive functions. 